\title{
Are African Governments as Unproductive as the Accelerated Development Report Implies?
}

\author{
Christopher Colclough
}

During the past two decades, most African governments rightly focussed on political consolidation, on the laying down of basic infrastructure ... and on the development of human resources. Relatively less attention was paid to production. Now it is essential to give production a higher priority - without neglecting these other goals.

To speed up development and make their economies more 'national', the new governments expanded the public sector. It is now widely evident that the public sector is over-extended, given the present scarcities of financial resources, skilled manpower and organisational capacity. This has resulted in slower growth than might have been achieved with available resources, and accounts in part for the current crisis.

$$
\begin{array}{r}
\text { Accelerated Development in sub-Saharan Africa: } \\
\text { an Agenda for Action } \\
\text { [World Bank 1981:4,5] }
\end{array}
$$

\section{Introduction}

The core prescriptions of the Report for achieving a resumption of growth in African economies are: first, to reform the structure of incentives, and in particular to allow the free market greater influence in resource allocation. Second, to reduce the size and to reform the role of government. The latter, which we are concerned with here, is aptly indicated by the quotations reproduced above. This article addresses two main questions: what evidence is there for claiming that the public sector in Africa is overextended'? Would its contraction facilitate the increase in production which the Report is concerned to achieve?

\section{Government 'Size' and Economic Performance}

The 'size' of government is not an unambiguous concept. One might think of the number of employees in the public sector, the magnitude of public spending, taxation or revenues, or of the extent of influence and involvement of government in total economic activity. The Report appears to associate 'size' with each of these variables at different times. The magnitude of the budget in relation to national resources would, however, be of central importance to any general critique of the size of government. Although the Report does not analyse public spending in Africa in relation to that in other regions, it is possible from the data in the Report to present such a comparison. The results are instructive.

Table 1 compares aspects of government expenditure and other economic indicators for 35 countries in sub-Saharan Africa (SSA), as well as for all countries, grouped according to low, middle and high income levels. The table shows that African countries have performed less well in terms of food production and general economic growth over the last two decades, and that they remain more dependent upon agriculture and are less industrialised than countries in other regions. However, when one considers government expenditure, the median values shown suggest that there is no significant diference between the proportion of GDP accounted for by public spending in low and middle income states in SSA, as compared to all such countries. In all groups government expenditure typically accounts for about one quarter of GDP. Moreover, as regards the functional breakdown of such expenditures, the median values for the two low income groupings reveal a remarkable correspondence. Almost exactly the same proportions of expenditure are typically allocated to defence, education, health, social security, other social services and economic services in African as in other low income countries. For the two groups of middle income countries, also, the proportions under each heading are not dissimilar, although the SSA group typically allocates more to general administration, education, agriculture and roads, and less to defence

\footnotetext{
1 These differences may partly be related to income, since the mean value for GNP per capita for the African middle income countries is little more than one-third the value for all such countries. See Table 1 .
} 
Comparison between African and other countries on the basis of selected economic indicators

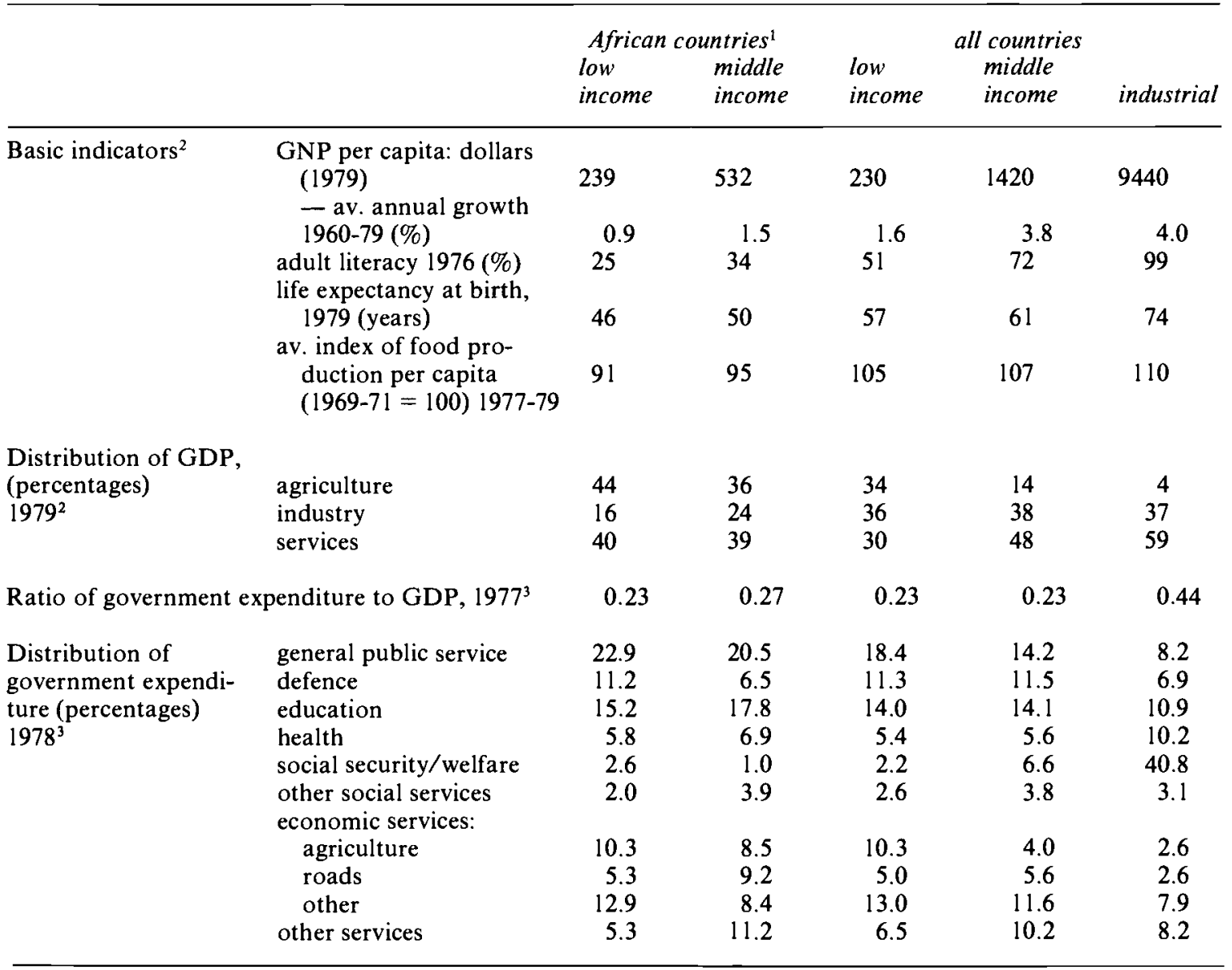

\footnotetext{
${ }^{1}$ Data are for 35 African countries. Oil exporters are excluded.

${ }^{2}$ Weighted means.

${ }^{3}$ Medians. Central government expenditure only. Parastatal operations included only to the extent that financial surpluses are transferred to the Treasury. Excludes debt service.
}

Source: World Bank 1981, Tables 1, 3, 40 and 41.

and social security than middle income countries in other regions. ${ }^{1}$

It is interesting in this connection to note that the proportion of GDP accounted for by government expenditure in the industrialised countries of the world is almost twice that typical of the poorer countries, including SSA. This high ratio is strongly influenced by the very large transfer payments for social security and welfare purposes which occur in the industrialised world. If one excludes these transfers, the remaining expenditure typically accounts for about 26 per cent of GDP This is again very similar to the proportions found in poorer countries. Thus, it seems that both the proportion of GDP spent by African governments, and the functional breakdown of these expenditures, represent typical expenditure patterns of other governments.

This conclusion itself suggests that the size of government, at least as measured by the proportion of GDP accounted for by public spending, is unlikely to explain the poor growth performance of African 
countries compared with those in other regions. It is useful to ask, however, whether differential growth performance within SSA is related in any way to differences in aggregate public spending. Table 2 compares the growth performance of 20 countries with the proportion of GDP accounted for by expenditure on public administration and defence. Inspection of the table reveals that there is no apparent relationship between these variables. Countries with high public expenditure ratios are as likely to experience moderate economic growth as those with low ratios. In summary, therefore, the statistical evidence on government spending available in the Report itself, provides no basis for the conclusion made by its authors that the rapid expansion of government activities has resulted in slower growth in SSA countries than would otherwise have been achieved.

Even if there is no empirical evidence to support the view that the expansion of the public sector has led to slower growth, it remains true, of course, that the resources employed by governments have associated opportunity costs. The mobilisation of resources by government precludes their use elsewhere in the economy, and the financing of government activity (primarily through taxation) will have negative effects upon output in other sectors. Thus, it is equally true that output in the private sector could be increased if the cost of government services were reduced, if unnecessary services were eliminated, or if existing services could be better or more cheaply provided by

\section{Table 2}

Comparison of the proportions of GDP spent upon public administration and defence with GDP growth rates, 1970-79'

\begin{tabular}{llll}
\hline & $\begin{array}{l}\text { expenditure } \\
\text { on public } \\
\text { admin. and } \\
\text { defence as } \\
\text { \% of GDP } \\
\text { (annual } \\
\text { average, } \\
1970-79)\end{array}$ & $\begin{array}{l}\text { lexpenditure } \\
\text { on public } \\
\text { admin. and } \\
\text { defence }\end{array}$ & $\begin{array}{l}\text { average annual } \\
\text { rates 1970-79 }\end{array}$ \\
\hline Upper Quartile & 16.1 & 8.6 & 3.5 \\
Second Quartile & 12.2 & 6.0 & 4.6 \\
Third Quartile & 9.2 & 6.3 & 2.4 \\
Lower Quartile & 6.5 & 8.1 & 5.0 \\
\hline
\end{tabular}

120 countries are included. Data show the unweighted mean values for each quartile, ranked on the basis of the proportion of GDP spent on public administration and defence (column 1).

Source: calculated from World Bank, 1981, Table 4.2. non-government agencies. It is for these reasons that, irrespective of the historical record, the World Bank no doubt believes itself to be on firm ground in arguing for a reduced future role for governments in Africa.

This diagnosis nevertheless suffers from a number of problems. In emphasising the importance of the tradeoff between the size of the government budget and that of private savings one should take care not to beg important questions concerning the use of savings by the private sector or the direct and indirect effect of public spending on production of marketed goods and services. In a number of SSA countries, reducing corporate taxation would do less to increase private domestic investment than it would to encourage enhanced repatriation of profits by foreign-owned enterprises. In others, it is by no means clear that increments to investment undertaken by the private sector have as much impact upon domestic welfare (as opposed to output measured in the conventional way) ${ }^{2}$ as would equal increments to public expenditure.

\section{What Private Alternatives?}

In a more practical sense, most of the activities now undertaken by African public sectors would, if governments suspended these activities, either not be done at all, or would be taken over by foreign, as opposed to domestically-owned enterprise. The search for an indigenous private sector which has the capital and manpower resources to occupy the space offered by a retreating government is unlikely to be successful. For example, in almost all countries where the government is involved in managing and financing major industrial ventures, such management was initially undertaken as a result of nationalisation of foreign-owned private corporations that had been operating domestically prior to independence. It is extremely unlikely that indigenous capitalists yet exist in sufficient numbers to take over more than a few of these enterprises in the event of their privatisation, even if that is deemed to be desirable. Moreover, the terms that would have to be offered to attract foreign capital into these ventures once again, would be unlikely to increase the absolute value of retained domestic benefits arising from their operations.

This is also true of government enterprises which were not created as a result of nationalisation. These typically include power, water and housing corporations, railways, airways and agricultural marketing organisations. In most countries their transfer to private hands would involve a re-introduction of foreign capital and management, with the exception

\footnotetext{
${ }^{2}$ In some cases even the impact on GDP may be higher. Effective education, health, transport and agricultural extension spending offer examples.
} 
(for some activities) of a small group of middle-income SSA countries (including perhaps Kenya, Nigeria, Zimbabwe) where well-developed indigenous private sectors have become established. In response to the view that the private sector should take on more of the activities presently conducted by government, the crucial question is: does an indigenous private sector with sufficient resources and experience to do so yet exist? In most cases the answer will be in the negative. ${ }^{3}$

\section{What Is To Be Cut?}

Perhaps because its authors are aware of some of these difficulties, the sections of the Report that deal with the parastatal sector advocate a broadly sensible set of measures to improve its efficiency, rather than its devolution from public ownership. Much more worrying, however, is that the main area which the Report recommends should increasingly be taken over by non-government agencies is the provision of basic services. Specifically, the Report argues that direct payment for government services in the areas of irrigation, health, and education should be sought. Villagers should increasingly be expected to finance medicines, schools, clinics, the construction of classrooms, pumps and wells. Private schools and clinics are advocated.

The reasons why the Bank feels that these are the main areas where cuts in government expenditure can be

\footnotetext{
3 This of course begs the question of whether the World Bank's Agenda is actually, as it asserts, neutral as to political and economic goals. Arguing for selectivity and efficiency in public enterprise may be consistent with some models of transition to socialism. General privatisation of industry, finance, commerce, transport and energy enterprises would seem to require a commitment to capitalism.
}

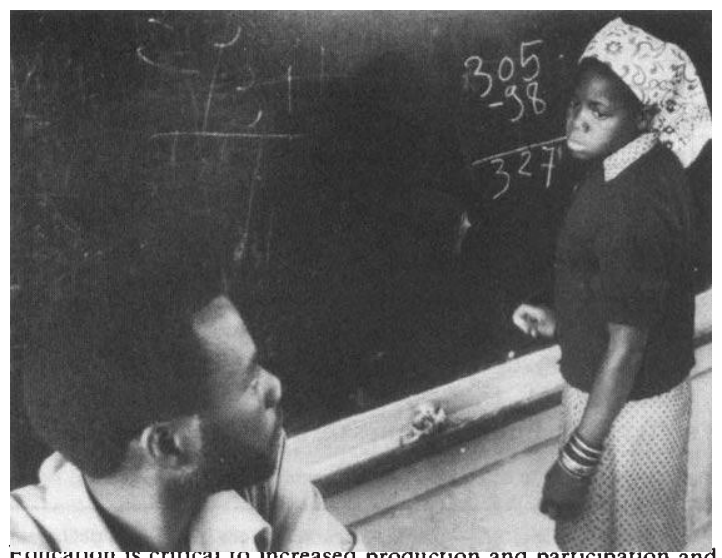

has made impressive advances, despite some macro policy - and micro empirical! - errors. (Primary school in Mozambique) satisfactorily made are not at all clear. Evidence suggests that fully or partially cost-covering charges for education and health services will result in large numbers of rural families being unable or unwilling to use such services. Moreover, allocating responsibility for their organisation and provision to village groups or private interests will in most cases result in a significant deterioration in the quality of the services provided. Thus, suggestions to shift the cost of providing basic services from government to the individuals who use them imply a reduction in the quantity and quality of services available to rural populations.

Yet the evidence for the productive value of expenditures upon basic education and health services is now overwhelming. The social rates of return attached to investment in education are widely documented. Available evidence clearly shows that the provision of primary schooling in particular is a highly profitable social investment. Similar points can be made in the health sector, particularly where nutritional levels are low. In such circumstances it is difficult to see how expenditure cuts in these areas could be generally justifiable.

It is as though the authors of the Report view all government recurrent expenditure as 'consumption' (in a real, rather than merely a national-accounting sense). This, indeed, is suggested by the first quotation reproduced at the beginning of this article. To pose such a sharp distinction between the development of human resources and the attention to be paid by policy makers to production strongly suggests that the purely economic value of investment in human resources is either being forgotten or ignored.

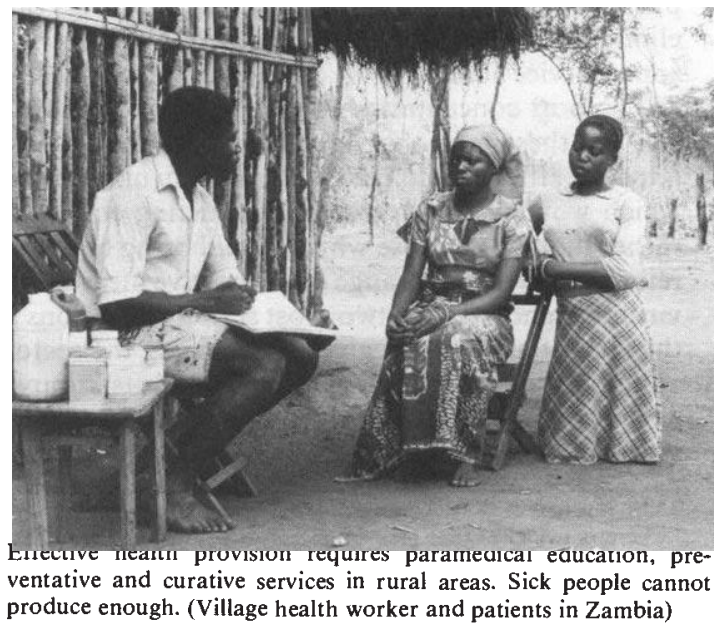


Perhaps the most striking aspect of these recommendations is that they appear to represent a clear volte face when compared with the central tendency of World Bank research and policy over the last decade. It is difficult to believe that the Report has been produced by the same organisation which has so often proclaimed (at least since Mr McNamara's Nairobi address in 1973) that growth does not necessarily imply development; that absolute poverty must be eradicated; that measures to improve income distribution are central concerns; and that the basic needs of the rural and urban poor must be urgently addressed. Public expenditures upon the provision of basic services have, in this sense, one very useful characteristic. They not only increase labour productivity, but the returns to these investments flow mainly to the users of the services concerned. In the case of poor rural and urban populations, therefore, government expenditures simultaneously promote both growth and distributional goals. If development in SSA is to be accelerated, government expenditures on these items must be increased in real terms over the medium-run. Ironically, the proposals for financing basic services made by the Report threaten to undermine - indeed to reverse - this process. ${ }^{4}$

\section{Are There Alternatives?}

If these central aspects of the Report's recommendations on the size of government are misguided, what, then, should have been given greater attention? There is no doubt that government budgets in Africa will have to be adjusted in the face of dramatically changed external circumstances. The problem is how to achieve this, whilst protecting, and even increasing, investments in the physical and human assets upon which the long-term growth of productivity in Africa depends. It will be recalled that budget reductions are primarily achieved by reduction in the cost of services, elimination of unnecessary activities, or by passing on some service functions to non-government agencies. The Report concentrates almost exclusively upon the last of these options, together with measures to improve efficiency in the public sector (mainly those which would improve output at existing cost levels, rather than upon those which would bring budgetary relief per se). Thus, a range of alternative measures are virtually ignored. The two most serious omissions are the lack of attention it gives to changing the sectoral allocation of budgetary resources, and its complete neglect of any serious analysis of the wage and salary structure.

\footnotetext{
${ }^{4}$ The reversal may be counterproductive in an additional sense. There is evidence that lack of access to education, basic health services and pure water are serious disincentives to living in rural areas. If so, making them increasingly available - physically and in terms of cost - would appear to deserve attention as an incentive to increased agricultural output.
}

As regards the first of these, the data in Table 1 shows that typically, up to one third of central government expenditure in Africa is allocated to general administration and defence. The proportion spent upon general administration is somewhat higher than that of other countries; defence expenditures compared with other regions are about the same for low-income countries, and somewhat less for the SSA middleincome group. Prima facie these items are expensive in both absolute and proportional terms. They could be reduced with minimal effects upon welfare, and the resources released could be allocated more productively within the public budget to education, health and economic services. Alternatively, they could enable some substitution of private investment for public current expenditures. Obviously this type of analysis raises both classification questions (especially within general administration) and major political issues - but, arguably, no more so than those prescriptions in the Report which focus upon cuts in social spending. At least one African state did make 10,000 administrators redundant in the mid 1970s and is attempting to cut nominal defence spending by over a third this year. At least some serious discussion of these issues would have pointed more forcefully to the real choices facing African governments in the area of budgetary priorities.

Second, and much more surprising, is that the Report makes no more than passing reference to the need for changes in the wage and salary structure. ${ }^{5}$ As a result, since the wage and salary bill represents a very high proportion of total government spending in all countries, the Report gives no serious attention to ways of reducing the costs of government services. There are three major reasons why such analysis is needed in the context of a discussion about the problems of adjustment in SSA economies. First, a real wage and salary cut over a one or two-year period presents one of the best opportunities for significant reductions in government expenditures over a short period. For example, a real cut of 10 per cent would bring savings equal to those which would be gained from the elimination of the whole of the defence budget in many SSA states. Second, it is completely unsatisfactory to analyse economic policy options without some discussion of which sections of the population are to carry the adjustment burden. In fact, the prescriptions of the Report would involve the heaviest costs being shouldered by the poorest members of the population. Small-holders have suffered declining incomes throughout Africa, because

\footnotetext{
$s$ One example cited - primary teacher wages ( $p 83$ ) - is perhaps not very fortunately chosen. Compared to GNP per household these range from 0.8 to 5.5 times as high, with 1.2 to 1.5 typical. This is well below levels for most petty administrative and semi-skilled production jobs.
} 
of droughts, wars and, to some extent, declining terms-of-trade. Adding to this the need to pay directly for publicly provided education, medical, irrigation and agricultural services is no small additional cost. Unless real wages and, especially, salaries are reduced, further budgetary adjustment can only be achieved by retrenchment. Thus newly impoverished people would be created whilst the incomes of those who remain in jobs would be protected. The lack of attention given to the wage and salary issue implies that the whole question of the distribution of the adjustment burden is completely overlooked. ${ }^{6}$

Finally, there is the question of the relationship between wages and the exchange rate. The Report correctly points out that exchange rates in Africa are typically over-valued, and recommends their downward adjustment. It argues that the exchange rate is a powerful tool for the correction of relative prices. It does not consider, however, that the extent to which nominal wages are allowed to move upwards to compensate for the inflationary impact of exchange rate movements can seriously modify, and in some cases even eliminate, the beneficial effects of devaluation in this sense. Thus in cases where unions are strong, or where there is a tradition of adjusting wages in line with prices, some change in the government's stance on wages policy will be required in addition to exchange rate manipulation. Otherwise devaluation may not have the positive effects upon output, employment and government expenditure which are envisaged by the Report.

\section{Toward a Different Agenda for Action}

In conclusion, therefore, we can say that there is no clear evidence that African public sectors are overextended relative to the proportional size of government budgets in other parts of the world. Nor have those countries in which government expenditure accounts for a smaller proportion of GDP performed better in terms of economic growth than other countries. It is nevertheless clear that government budgets will need to be trimmed, relative to GDP and, in some cases, absolutely over the short/medium term, in response to deteriorating external economic circumstances, the balance of payments difficulties which these have helped to create and resultant weakening of revenue bases. In this regard, we have found the Report seriously lacking in its analysis of the policy choices faced by SSA governments. In particular it places too much emphasis upon measures which would effectively reduce the availability of basic services to African populations, and insufficient emphasis upon measures to change the sectoral structure of government spending, and to reduce the costs of public services. In particular, the lack of attention paid to needed changes in the wage and salary structure is a major omission in both analytic and policy terms.

\footnotetext{
${ }^{6}$ In certain cases the problem may take the form of rapid government employment growth, financed in part by falling real wages and salaries. Malawi and Tanzania (where the share of wages and salaries in the recurrent budget appears to have fallen from 60 per cent in 1961 to 30 per cent in 1981) may be examples. In such cases cutting down on new government hiring may be the most critical saving possible.
} 